\title{
Morfologia da glândula mamária de gambás da espécie Didelphis sp associada ao modelo marsupial
}

\author{
Vivian Yochiko Samoto', Maria Angélica Miglino³, Carlos Eduardo Ambrósio², Flávia Thomas Verechia Pereira \\ Marcelo Cardoso de Lima ${ }^{1}$ \& Ana Flávia de Carvalho ${ }^{2}$
}

Biota Neotropica v6 (n2)-http://www.biotaneotropica.org.br/v6n2/pt/abstract?article+bn01306022006

Recebido em 23/10/05.

Versão revisada recebida 20/03/06.

Publicado em 01/05/06.

\begin{abstract}
${ }^{1}$ Ms em Anatomia dos Animais Domésticos e Silvestres - FMVZ/USP- São Paulo (vysamoto@usp.br)
${ }^{2}$ Prof. Dr. Em Ciências Morfológicas - UNIFEOB - São João da Boa Vista (labmicro03@unifeob.br)

${ }^{3}$ Prof. Titular do Departamento de Anatomia dos Animais Domésticos e Silvestres. FMVZ/USP (miglino@usp.br)

${ }^{4}$ Prof. Dr. Em Ciências Morfológicas - UNESP/ Dracena (fverechia@unesp.dracena.br)
\end{abstract}

\begin{abstract}
Samoto, V.Y.; Miglino, M.A.; Ambrosio, C.E.; Pereira, F.T.V.; Lima, M.C. and Carvalho, A.F. Opossum (Didelphis sp) mammary gland morphology associated to the marsupial model. Biota Neotrop. May/Aug 2006 vol. 6, no. 2, http:// www.biotaneotropica.org.br/v6n2/pt/abstract?article+bn01306022006. ISSN 1676-0603
\end{abstract}

Vertebrates with short period of pregnancy, the marsupials tend to have small and dependent younglitters. The period of pregnancy varies of 14-15 days and, the younglitters finish his development in the pouch, being this period, considered as an external gestation by some authors. The mammary gland is located internally to the pouch, in number of 11 the papilae which were connected to the younglitters come more developed, in lenght. In the microscopic analysis, the mammary gland of the opossum resembles each other to the one of the domestic mammals, except for the absence of the muscle sphincter papillae.

Key words: Opossum, mammary gland and papillae

\section{Resumo}

Samoto, V.Y.; Miglino, M.A.; Ambrosio, C.E.; Pereira, F.T.V.; Lima, M.C. and Carvalho, A.F. Morfologia da glândula mamária de gambás da espécie Didelphis sp associada ao modelo marsupial. Biota Neotrop. May/Aug 2006 vol. 6, no. 2, http:// www.biotaneotropica.org.br/v6n2/pt/abstract?article+bn01306022006. ISSN 1676-0603

Vertebrados com períodos gestacionais curtos, os marsupiais tendem a ter proles pequenas e dependentes. O período gestacional dos gambás varia de 14-15dias e os filhotes terminam o seu desenvolvimento no marsúpio e este período é considerado como uma gestação externa por alguns autores. A glândula mamária localiza-se internamente ao marsúpio. A cadeia mamária de cada fêmea era composta por 11 papilas mamárias e aquelas papilas que se encontravam conectadas aos filhotes exibiam um comprimento maior em relação às outras. Histologicamente, a glândula mamária dos gambás assemelhase às dos mamíferos domésticos, exceto pela ausência do músculo esfíncter papilar no teto.

Palavras-chave: Gambá, glândula mamária e papila mamária 


\section{Introdução}

Zeller (1999) classificou os gambás como pertencentes ao Filo Chordata, a Ordem Marsupialia e a Família Didelphidae. A Ordem dos Marsupiais (Marsupialia) foi descoberta pelos Europeus em 1500 a.C. sendo observada em 3 continentes: América do Norte, do Sul e Austrália.

A palavra "gambá”, segundo Sampaio, é corruptela de guaambá = seio oco, saco vazio, referência ao marsúpio. No Brasil o seu principal representante é o Didelphis albiventris, sendo que estes possuem aproximadamente $23 \mathrm{~cm}$ de comprimento, cauda parcialmente glabra, são plantígrados, sendo que o primeiro dígito do membro pélvico é desprovido de unha (Nowak, 1997). Possuem hábito noturno, são onívoros, tendem a ter proles pequenas e dependentes, como conseqüência, é observado um número pequeno de tetos (Hildelbrand, 1995).

Tyndale-Biscoe \& Renfree (1987) afirmam que a lactação caracteriza fundamentalmente todos os mamíferos e é o principal padrão de evolução reprodutiva dos mesmos, sendo este período considerado como uma gestação externa por Adamski \& Demmer (1999), pois o filhote é completamente dependente do leite nesta fase. Segundo Orr (1986) a posição das papilas varia muito nas diferentes espécies, são sempre pares e os ductos abrem-se em mamilos mais elevados.

Garcia \& Gonçalves (1984) não encontraram conexões orgânicas entre a papila mamária e o feto (Didelphis azarae), contudo, foi observado um aumento do volume da papila mamária dentro da cavidade oral do feto e, a imbricação entre o extrato córneo da mama, palato e língua promovem uma maior fixação entre a papila e o feto, contribuindo consequentemente, no ato da sucção. Os fetos de Didelphis virginiana estão acomodados em uma bolsa bem formada que normalmente contém 13 papilas mamárias, embora, um ou dois pares craniais da cadeia mamária, nem sempre são funcionais Reynolds (1952) e Burns \& Burns (1957). Cutts, Krause \& Leeson, 1978 observaram que os fetos que se encontravam associados às papilas mamários posteriores, ou caudais, eram os mais pesados da ninhada.

\section{Material e Métodos}

Foram analisadas fêmeas provenientes do criatório da UNESP/Araçatuba (coordenadas geográficas: longitude

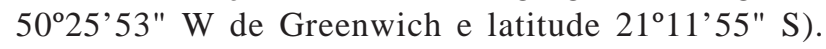
Macroscopicamente as fêmeas adultas foram medidas em crown-rump, sendo também realizada a medição do marsúpio e contagem do número de papilas mamárias.

O material coletado, glândula e papila mamária, foi fixado em formol 10\%. Posteriormente desidratados com séries de álcoois em concentrações crescentes (de 70 a $100 \%$ ) e diafanizados em xilol seguido de inclusão em paraplast (Paraplast Embedding Media- Paraplast Plus, Ox- ford Lab., USA) (Behmer,1976) guardando suas devidas posições “in situ”. As papilas foram incluídas separadamente.

As glândulas incluídas foram cortadas, em um micrótomo LEICA RM 2165, com espessura média de 5mm e os cortes foram corados com picrossirius (Junqueira, et al. 1979), hematoxilina-eosina (Behmer, 1976). Também foi estimada a idade dos filhotes de acordo com o trabalho realizado por Cutts et al. (1978) no qual relaciona a idade do animal com as características fenotípicas.

\section{Resultados}

De todas as fêmeas, quatro portavam filhotes em seu marsúpio. A idade estimada das duas primeiras ninhadas foi de 15 dias, pois os filhotes apresentavam as seguintes características: orelhas bem desenvolvidas, os membros pélvicos encontravam-se em estágio de desenvolvimento (relacionado ao tamanho) equivalente aos membros torácicos, presença de garras nos membros anteriores e garras emergindo nos posteriores (Figuras 1a e 1b). Na terceira ninhada observada, os filhotes apresentavam-se com: imaturidade facial acentuada, membros torácicos mais desenvolvidos que os pélvicos, os olhos, as orelhas e a boca ainda encontravam-se fechados, entretanto, existia uma abertura na região anterior da boca onde ocorria a conexão com o teto. Estimou-se desta forma a idade aproximada em torno de oito dias (Figura 2). Na quarta ninhada observamos que os filhotes apresentavam-se com pêlos distribuídos pelo corpo, membros torácicos e pélvicos bem desenvolvidos, presença de garras em ambos os membros, características faciais bem definidas como presença de vibrissas, olhos proeminentes, porém ainda fechados e orelhas bem desenvolvidas (semelhante ao um indivíduo adulto). Com base nestas características, estimamos a idade aproximada em 60 dias (Figura 3).

O marsúpio localiza-se na região abdominal caudal, possui forma de ferradura e em seu interior observam-se as papilas mamárias em forma de “U”, em número de 11, dispostas aos pares exceto uma que se localizava centralmente, sendo que, as papilas que se encontravam conectadas aos filhotes encontravam-se mais desenvolvidas, em relação ao comprimento, e as restantes apresentavam aspecto inativo (Figura 4, 4a, 4b). A origem vascular da glândula mamária de Didelphis sp foi marcada principalmente pelas artérias e veias mamárias superficiais que percorrem a região ventral do animal no sentido crâniocaudal. No marsúpio, os vasos de maior calibre formam em sua base um "U” invertido, que por sua vez, emitiram vasos de menor calibre em forma radiata e circunvoluta, originando uma coroa ao redor do órgão. Outra fonte de nutrição seria através das artérias e veias epigástricas, com origem no tronco pudendo epigástrico dos membros pélvicos, porém, a maior fonte de nutrição é marcado pelos vasos mamários superficiais (Figura 5). 
Pôde-se observar através de análise em microscopia de luz que a papila mamária é revestida por um epitélio do tipo estratificado pavimentoso queratinizado, abaixo do epitélio podemos observar tecido conjuntivo frouxo, feixes de fibras musculares lisas, ductos com epitélio biestratificado e a ausência do músculo esfíncter papilar próximo ao óstio papilar (Figura 6, 6a). A glândula mamária apresenta o mesmo epitélio de revestimento, sendo que o tecido conjuntivo é rico em glândulas sebáceas e sudoríparas. Mais internamente é observado o epitélio glandular composto por glândulas túbulo-alveolares (Figuras 7 e 8). Nas fêmeas portadoras de filhotes foi observado um grande número de mitoses no tecido glandular, ressaltando então, que o crescimento das mesmas está atrelada ao desenvolvimento dos filhotes.

\section{Discussão}

Hildebrand (1995) relata que os marsupiais têm por característica apresentar um pequeno número de papilas mamárias devido a sua característica reprodutiva, contudo, devido à quantidade de papilas mamárias encontradas por marsúpio (11) mostra que estes animais apresentaram uma alta viabilidade para criar um grande número de filhotes.

Em 1986, Orr afirmou que a posição das glândulas varia nas espécies, são sempre aos pares e os ductos abremse em mamilos mais elevados. Com relação à posição da glândula mamária concordamos com a afirmativa feita pelo autor, visto que podemos comparar a disposição das glândulas e papilas mamárias dos animais domésticos com o marsupial, porém discordamos quando o autor de refere ao número par de glândulas e conseqüentemente de papilas mamárias, pois como foi observado, o Didelphis sp este possui 11 papilas mamárias, sendo que uma delas está disposta centralmente.

Como referido por Garcia \& Gonçalves (1984) também não foi observado estrutura macro ou microscópica que fizesse conexão da boca do filhote com a papila mamária, este dado é coerente com nossos achados.

Através de análise macroscópica pudemos observar que há um nítido desenvolvimento das papilas mamárias nas fêmeas jovens, contudo o mesmo não foi observado nos machos jovens e adultos como relatado por Robinson, et al (1991).

Nos filhotes de idade aproximada de oito dias e tamanho de 2,94 cm já era observado a presença do marsúpio e das papilas mamárias, enquanto que nos machos, já podem ser observados os testículos e o pênis, sendo que Ullmann (1993) relatou que esse dimorfismo sexual já pode ser observado em filhotes com 12 mm (ou $1,2 \mathrm{~cm}$ ) de comprimento.

\section{Agradecimentos}

Agradeço a Fundação de Amparo à Pesquisa do Estado de São Paulo pelo financiamento e oportunidade oferecida do desenvolvimento de um projeto que subsidia o conhecimento da fase reprodutiva de um animal da fauna brasileira. A UNIFEOB por autorizar o uso dos laboratórios para realização das análises nestes animais e a UNESP, Campus Araçatuba, por ter cedidos os animais.

\section{Referências bibliográficas}

BURNS, R. K. \& BURNS, L. M. 1957. Observations on the breeding of the American Opossum in Florida. Revue Suisse de Zoologie 64:595-605

ADAMSKI, F. M \& DEMMER, J. 1999. Two stages of increase IgA transfer during lactation in the marsupial, Trichosurus vulpecula( Brushtail possum). Journal of Immunology. v. 162: 6009-6015.

BEHMER, O. A.; TOLOSA, E. M. C. \& FREITAS NETO, A. G. 1976. Manual de Técnicas para Histologia Normal e Patológica. São Paulo: Edart. p. 315.

CUTTS, J. R.; KRAUSE, J. \& LEESON, C. R. 1978. General Observation on the Growth and Development of the Young Pouch Opossum, Didelphs virginiana. Biology of Neonate. v.3, p.264-272.

GARCIA, P. J. \& GONÇALVES, R. P. 1984. Histological and ultrastrutuctural observations of the attachment between the oral cavity of the fetus and the nipple of the nother in opossum (Didelphis azarae). Anatomischer Anzeiger. v.157.p.151-157.

HINDEBRAND, D. M. 1995. Análise da Estrutura dos Vertebrados. São Paulo. Atheneu. p.700.

JUNQUEIRA, L. C. V.; BIGNONAS, G. \& BRETAN, R. P. 1979. Picrosirius staining plus polarization microscopy, a specific method for collagen detection in the tissue sections. Histochemical Journal. v. 11, p. 447-255.

NOWAK, R.M. 1999. Marsupialia: Didelphidae In: Walker’s Mammals of the World on line 5.1. Johns Hopkins University Press, Baltimore, 1997. Disponível em:http:// www.press.jhu.edu/books/walkers mammals of the world/w-index-g.htm . Acesso em: 8 set. 2003. Anatomischer Anzeiger 238. p. 117-230.

ORR, R. T. 1986. Biologia dos Vertebrados. 5ed. São Paulo: Roca. p.508.

ROBINSON, E. S.; RENFREEE, M. B.; SHORT, R. V. \& VANDEBERG, J. L. 1991. Mammary gland in male marsupials. 2. Development ot teat primordia in Didelphis vieginiana and Monodelphis domestica. Reproduction, Fertility and Development. v.3. p. 295-301.

REYNOLDS, H. C. 1952. Studies on reproduction on the opossum (Didelphis virginiana virginiana). University of California Publications in Zoology, v. 52, p. 223-284. 
TYNDALE-BISCOE, H. ; RENFREE, M. 1987. Reproductive Phisiology of Marsupials. Experimental Pysiology. p. 413.

ULLMANN, S. L. 1993.Differentiation of the gonads and initiation of mammary gland and scrotum development in the bruhtailk possum Trichosurus vulpecula (Marsupilia). Anatomy and Embryology. v. 187. p. 475-485.

ZELLER, U. 1999. Mammalian reproduction: origin and evolutionary transformations. Zoologischer Anzeiger, 238. p. 117-130.

Título: Morfologia da glândula mamária de gambás da espécie Didelphis sp associada ao modelo marsupial.

Autores: Samoto, V.Y.; Miglino, M.A.; Ambrosio, C.E.; Pereira, F.T.V.; Lima, M.C. and Carvalho, A.F.

Biota Neotropica, Vol. 6 ( número 2 ): 2006

http://www.biotaneotropica.org.br/v6n2/pt/ abstract?article+bn01306022006

Recebido em 23/10/05 - Versão revisada recebida 20/03/ 06 - Publicado em 01/05/06.

ISSN 1676-0603 

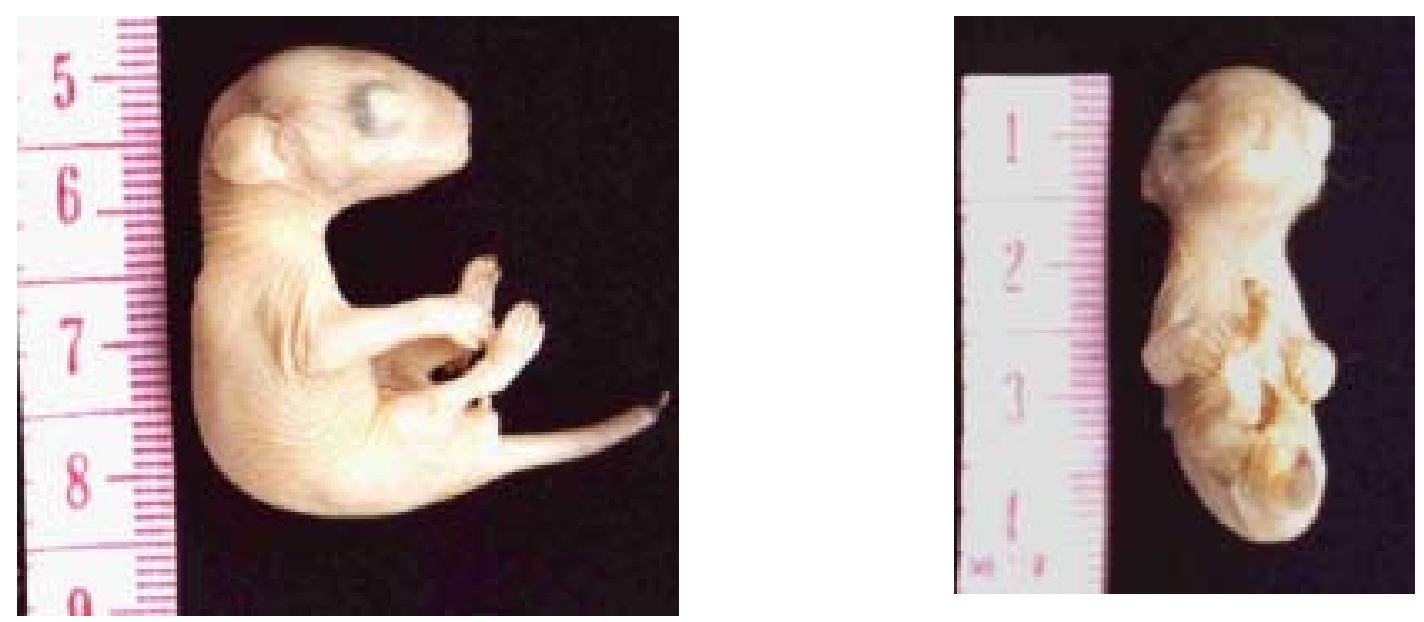

Figura 1 - Animal com idade aproximada de 15 dias. (A) Notar que os membros torácicos e pélvicos apresentam o mesmo grau de desenvolvimento, com a presença de garras, maturidade facial e orelhas bem desenvolvidas; (B) Observar a maturidade facial com presença de vibrissas, olhos proeminentes e orelhas bem desenvolvidas.

Figure 1 - Animal with 15 days of age. (A) The toracic and pelvic members shows the same degree of development in lenght, with the presence of claws, face maturity and well developed ears; (B) The face maturity is marked with vibrisses, prominent eyes and developed ears. 


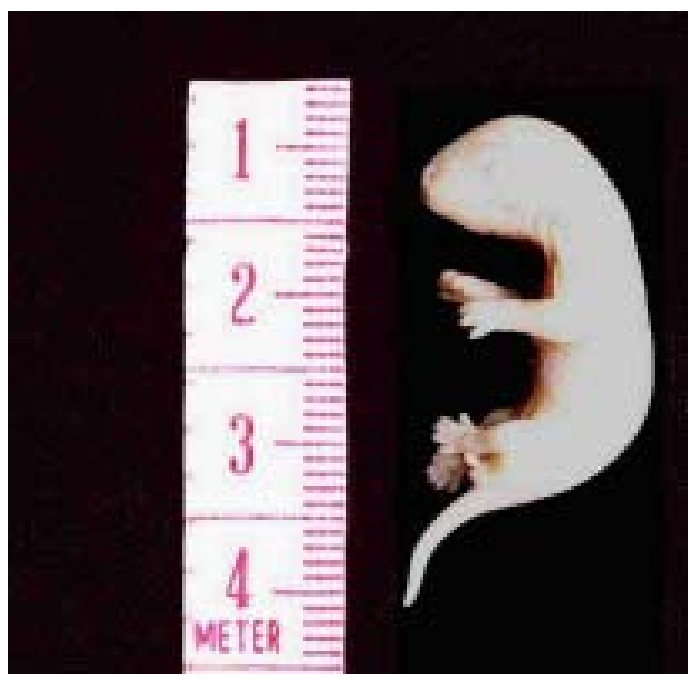

Figura 2. Filhote com idade aproximada de 8 dias. Apresentava imaturidade facial acentuada, membros torácicos mais desenvolvidos que os pélvicos, os olhos, as orelhas e a boca ainda encontravam-se fechados, entretanto, existia uma abertura na região anterior da boca onde ocorria à conexão com o teto.

Figure 2. Younglitter with 8 days of age. It presented accented face immaturity, thoracic members more developed than the pelvic, the eyes, the ears and the mouth still met closed, however, existed an opening in the anterior region of the mouth where it occurred to the connection with the nipple. 


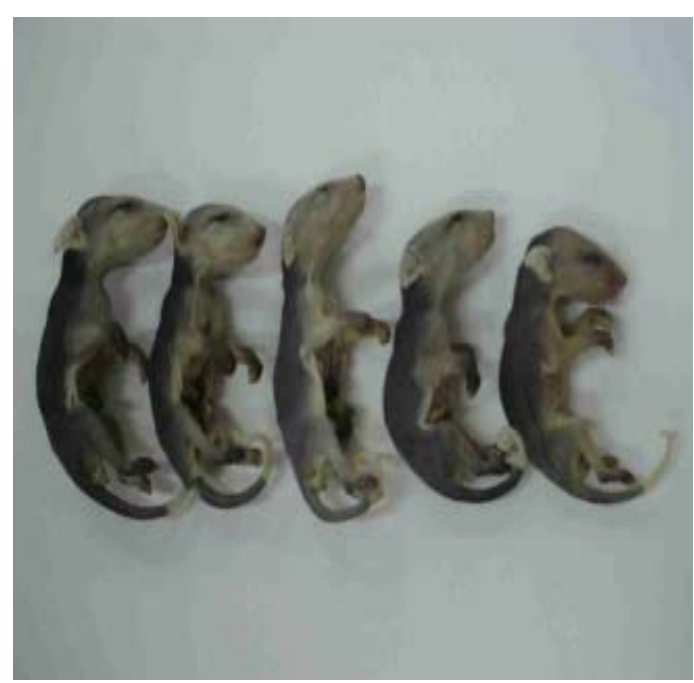

Figura 3. Filhotes com pêlos distribuídos pelo corpo, membros torácicos e pélvicos desenvolvido com presença de garras, características faciais similares ao indivíduo adulto.

Figure 3. Younglitters with coats distributed for the body, thoracic and pelvic members developed with presence of claws in both members, face characteristics similar to the one adult individual. 

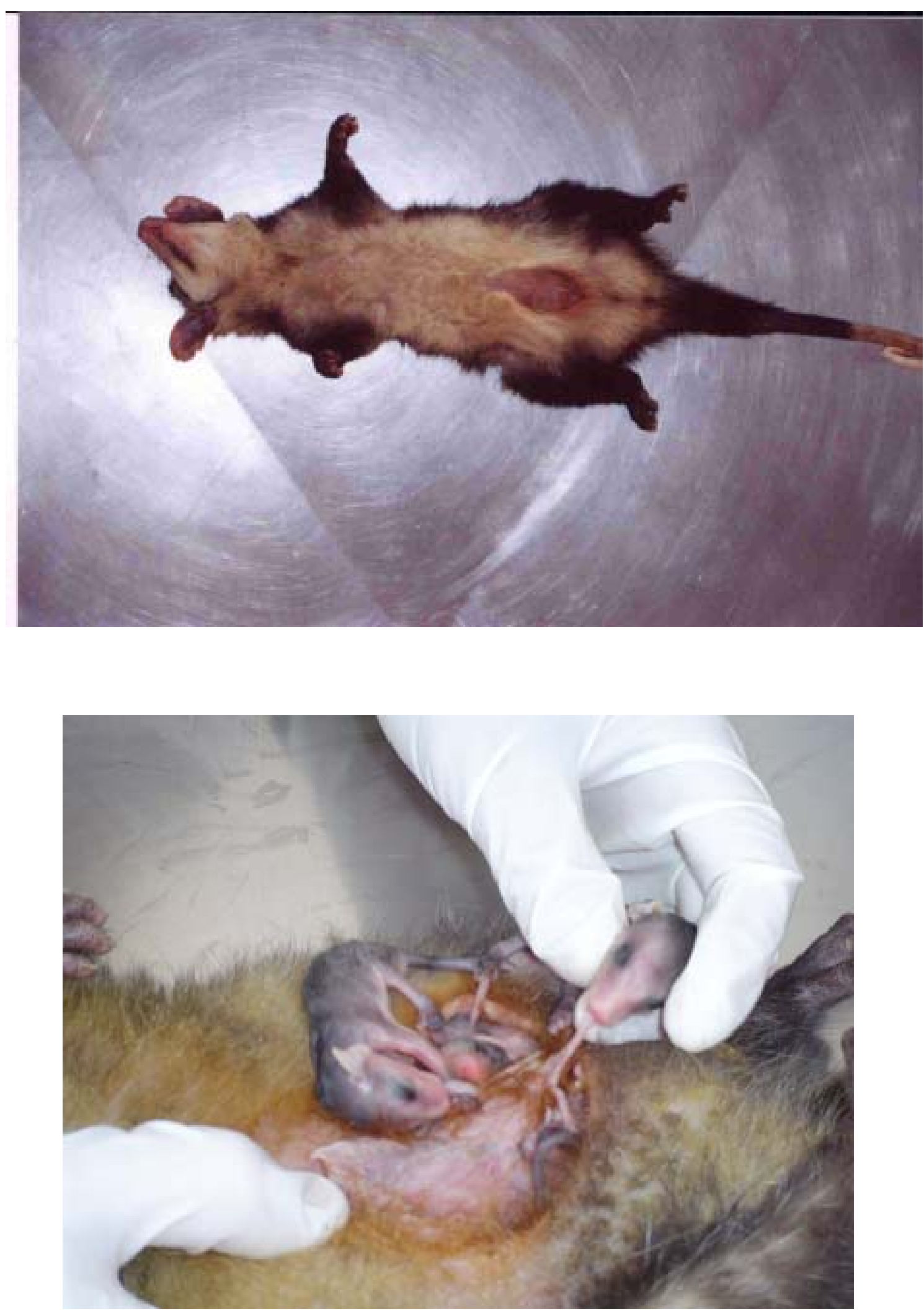

Figura 4. Localização do marsúpio em região abdominal. (A) Fotografias de papilas mamárias de fêmea portadora de filhotes; (B) Observar o desenvolvimento em comprimento das papilas que se encontravam conectadas aos filhotes.

Figure 4. The pouch is located in abdominal region. (A) Female mammary gland photograph wich carried younglitter; (B) Observe the development in length of papilas that was connected to the younglings. 


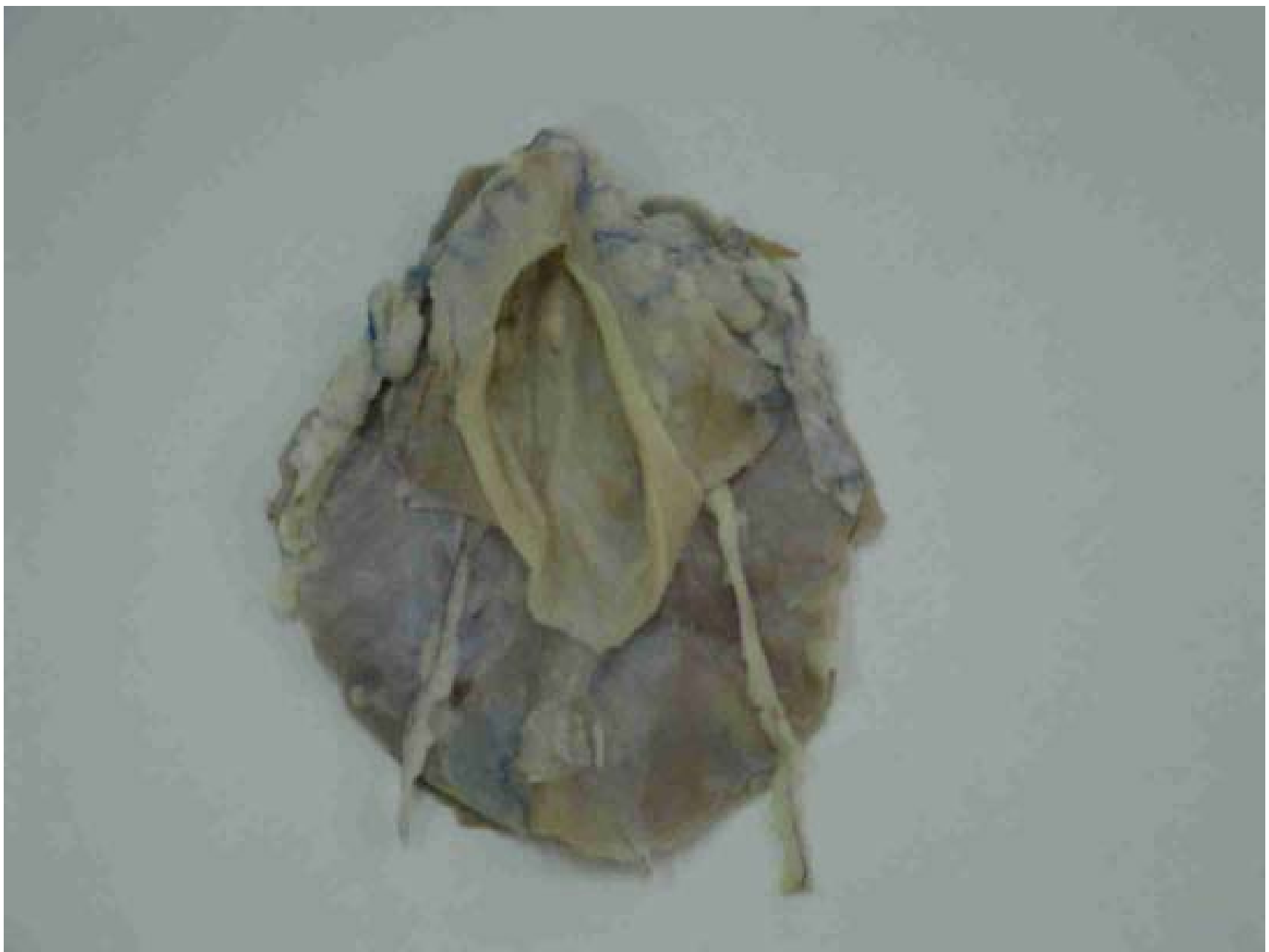

Figura 5. Molde vascular do marsúpio com injeção de látex.

Figure 5. Pouch vascular mold with latex injection. 


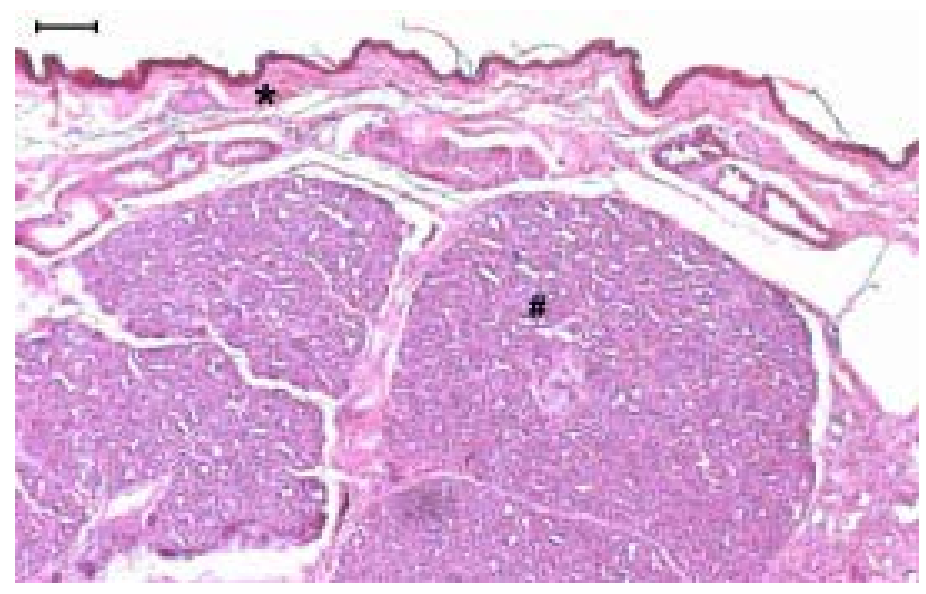

Figura 6. Fotomicrografia da glândula mamária. Observe o epitélio estratificado pavimentoso queratinizado, tecido conjuntivo $\left({ }^{*}\right)$ e tecido

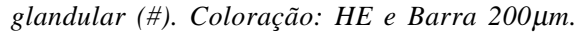

Figure 6. Photomicrograph of mammary gland. Observe the epithelium stratified squamous keratinizing, connective tissue (*) end glandular

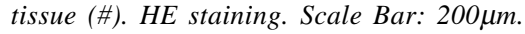


Figura 7. Fotomicrografia da porção distal da papila mamária. Notar a ausência do músculo esfíncter papilar. Coloração HE. Barras $200 \mu$ m. Figure 7. Photomicrograph of papila distal portion. Observe the papilar muscle is absent. HE staining. Scale Bar: 200 $\mu \mathrm{m}$. 


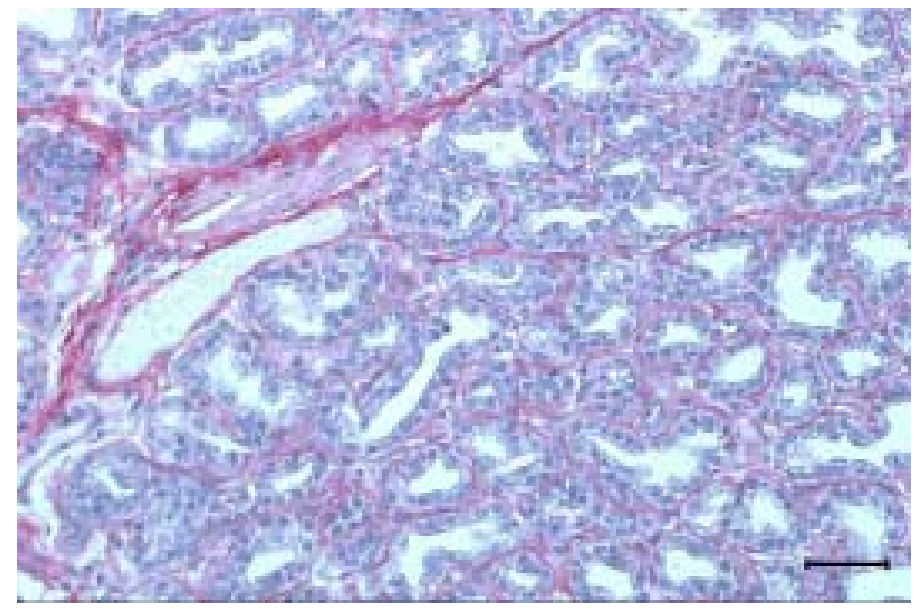

Figura 8. Fotomicrografia do tecido glandular. Observe o tecido conjuntivo entre as glândulas e com o espessamento do mesmo há divisão

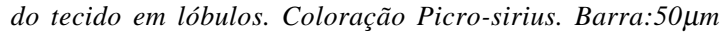

Figure 8. Photomicrograph of glandular tissue. Observe the connective tissue between the tubular gland and the same divided the glandular tissue in lobules. Picro sirius staining. Scale bar: $50 \mu \mathrm{m}$. 